\title{
CITRA FISIK TOKOH SITI ZUBAIDAH DALAM SYAIR SITI ZUBAIDAH
}

\author{
Noor Indah Wulandari dan Novia Winda \\ STKIP PGRI Banjarmasin \\ Jalan Sultan Adam, Komplek H. Iyus, No. 18 RT.23 Banjarmasin \\ Kalimantan Selatan. Kode pos 70121, \\ email: Indah_wulandari@stkipbjm.ac.id.,noviawinda05@stkipbjm.ac.id.
}

\begin{abstract}
ABSTRAK
Penelitian berkenaan dengan citra wanita dalam syair Siti Zubaidah menggunakan pendekatan feminisme. Citra wanita sangat berkaitan erat dengan karya sastra, secara gamblang wanita secara aspek yang unik dan menarik untuk dibahas dan ditulis dalam karya sastra. Karya sastra selalu menyediakan ruang terbuka pada setiap objek yang diperbincangkan. Penelitian ini difokuskan pada citra wanita dari segi fisik dalam syair Siti Zubaidah.

Pendekatan yang digunakan dalam penelitian ini adalah pendekatan feminisme.Penelitian ini menggunakan dua jenis data, yakni data primer dan data sekunder. Data primer diambil berdasarkan data lisan/tuturan. Data lisan/tuturan berupa frasa, klausa, kata, kalimat yang terdapat dalam Syair Siti Zubaidah. Data sekunder berasal dari buku dan sumber terkait dengan Syair Siti Zubaidah. Dalam pengumpulan data peneliti menggunakan teknik rekam, teknik simak catat, dan teknik dokumentasi.Teknik pemeriksaan keabsahan data yang menggunakan triangulasi metode dan teori.

Hasil penelitian ini menemukan Citra wanita dari segi fisik dalam Syair Siti Zubaidah, yakni: (a) kecantikan, (b) postur tubuh, dan (c) penampilan.
\end{abstract}

Kata Kunci: citra, fisik, syair, Siti Zubaidah

\section{PENDAHULUAN}

Sastra berkaitan dengan hasil cipta manusia, baik yang anonim maupun yang diketahui pengarang atau penciptanya. Salah satu jenis karya sastra yaitu syair. Syair disebut juga dengan istilah narrative poetry "puisi kisahan" yaitu cerita yang digubah dalam bentuk puisi. Berbeda dengan pantun, syair bersajak a a a a dan keempat lariknya merupakan isi atau makna yang terkandung dalam syair itu. Sebagaimana syair Siti Zubaidah, syair Melayu abad ke-19 merupakan salah satu dari beberapa ceita melayu yang menggabungkan unsur-unsur dari pengaruh India dan Timur Tengah.

Dalam syair Siti Zubaidah menekankan kesetiaan kepada suaminya dan Tuhan, menelantarkan tugasnya sebagai ibu untuk melanjutkan perang. Pada akhirnya, menurut pakar sastra Malaysia Barbara Watson Andaya, "kesetiaan, kesalehan, dan kepasrahan kepada nasib, bahkan ketika suami tidak setia, memberikan Siti Zubaidah status sebagai Permaisuri. Menelaah sastra feminis yang terdapat dalam syair Siti Zubaidah sangatlah menarik. Kesetaraan jender 
memang penting, namun bukan berarti melupakan kodrat sebagai seorang perempuan secara fitrahnya.

Peneliti mengangkat penelitian berkenaan dengan citra wanita dalam syair Siti Zubaidah menggunakan pendekatan feminisme. Citra wanita sangat berkaitan erat dengan karya sastra, secara gamblang wanita secara aspek yang unik dan menarik untuk dibahas dan ditulis dalam karya sastra. Karya sastra selalu menyediakan ruang terbuka pada setiap objek yang diperbincangkan.

Citra wanita tercermin pada tokoh dan penokohan yang menunjukkan pada orangnya, perilaku cerita. Penokohan dan karakter menunjukkan pada perempuan tokoh-tokoh tertentu dengan watak-watak tertentu dalam sebuah cerita. Dapat dikatakan bahwa tokoh cerita individu rekaan yang mempunyai watak dan prilaku tertentu sebagai pelaku mengalami peristiwa dalam cerita. Hal ini searah dengan pendapat Aminudin dalam Lizawati (2015: 4) bahwa tokoh adalah pelaku yang mengembangkan peristiwa dalam cerita fiksi sehingga peristiwa itu mampu menjalin suatu peristiwa. Istilah tokoh mengacu pada orangnya, pelaku cerita. Tokoh adalah satu diantara unsur yang penting dalam cerita atau rekaan.Citra perempuan ialah semua wujud gambaran mental spiritual dan tingkah laku keseharian yang terekspresi oleh tokoh perempuan. Baik itu sebagai mahluk individu yang mencakup aspek fisik, psikologinya, maupun citra wanita dalam aspek sosial Sugihastuti dalam Muliana (2016: 3).

\footnotetext{
"Sejak dulu, karya sastra telah menjadi cultre regime dan memiliki daya pikat kuat terhadap persoalan gender. Paham tentang wanita sebagai orang lemah lembut, permata, bunga, dan sebaliknya pria sebagai orang yang cerdas aktif, dan sejenisnya selalu mewarnai sastra kita. Citra wanita dan pria tersebut seakan-akan telah mengakar di benak penulis sasra. Sampai sekarang, paham yang sulit dihilangkan adalah terjadinya hegmoni pria terhadap wanita. Hampir seluruh karya sastra, baik yang dihasilkan oleh penulis pria maupun wanita dominasi pria selalu lebih kuat. Figur pria terus menjadi the authority, sehingga mengsumsikan bahwa wanita adalah impian. Wanita selalu sebagai the second sex, warga kelas dua dan tersubordinasi" (Endraswara, 2013: 143).
}

Secara psikis, perempuan dicitrakan sebagai makhluk yang feminis, yang dicirikan olehnya berbagai wujud tingkah laku. Di dalam masyarakat, sebagai akibat dari aspek biologisnya, perempuan bernilai lebih rendah dari laki-laki. Penilaian ini datang dari lawan jenis dan lingkungan masyarakat yang mengelilinginya. Dari aspek fisik wanita dicitrakan sebagai makhluk lemah, tidak berdaya, dan menempati peran yang tidak membahagiakan. Wanita adalah jenis kelamin manusia. Wanita juga dapat diartikan sebagai perempuan dewasa, KBBI (dalam Evin Noviyanti, 2005:5). 
Dalam penelitian ini lebih difokuskan pada citra wanita dalam syair Siti Zubaidah dari segi fisik. Sugihastuti dalam Muliana (2016: 9) menjelaskan bahwa wujud fisik secara lahiriah meliputi kecantikan, postur tubuh, penampilan dan sebagainya. Selain penggambaran oleh pengarang, citra fisik tokoh juga diungkapkan pengarang melalui tokoh-tokoh yang berperan dalam novel. Pada penelitian ini terdapat tiga indikator fisik wanita yaitu kecantikan, postur tubuh, dan penampilan tokoh wanita.

\section{METODE}

Pendekatan merupakan penentuan dalam langkah meneliti, dengan kata lain pendekatan merupakan cara pandang dan mendekati suatu objek. Menurut Devi dalam aminuddin (1991:40) "pendekatan adalah dasar yang digunakan dalam mendekati sesuatu atau menyikapi sesuatu. Pendekatan tersebut merupakan prinsip dasar atau landasan yang digunakan oleh seorang saat mengapresiasi karya sastra".

Penelitian ini akan mengkaji tentang citra wanita dalam syair Siti Zubaidah dari segi fisik.Dengan demikian, pendekatan yang digunakan dalam penelitian ini adalah pendekatan feminisme. Menurut Endraswara (2013:146) "Pendekatan feminisme adalah upaya pemahaman kedudukan dan peran perempuan seperti yang tercermin dalam karya sastra". Dengan kata lain feminisme adalah studi yang memfokuskan analisisnya pada perempuan.

Penelitian ini menggunakan dua jenis data, yakni data primer dan data sekunder. Data primer diambil berdasarkan data lisan/tuturan. Data lisan/tuturan berupa frasa, klausa, kata, kalimat yang terdapat dalam Syair Siti Zubaidah. Data sekunder berasal dari buku dan sumber terkait dengan Syair Siti Zubaidah. Sumber data dalam penelitian ini adalah informan yang menyampaikan Syair Siti Zubaidah.

Teknik pengumpulan data yang digunakan seperti diuraikan Arikunto (1998:100) menyebutkan bahwa metode pengumpulan data adalah cara-cara yang digunakan peneliti untuk mengumpulkan data. Dalam pengumpulan data peneliti menggunakan teknik rekam, teknik simak catat, dan teknik dokumentasi.

Teknik pemeriksaan keabsahan data yang digunakan dalam penelitian ini adalah triangulasi. Menurut Moleong (2005:330) triangulasi adalah teknik pemeriksaan keabsahan data yang memanfaatkan sesuatu yang lain. Pemeriksaan ini dilakukan untuk membandingkan data dengan sumber lainnya. Penelitian ini menggunakan triangulasi metode dan triangulasi teori. 


\section{HASIL DAN PEMBAHASAN}

\section{Citra Wanita dari Segi Fisik}

Sugihastuti dalam Muliana (2016: 9) menjelaskan bahwa wujud fisik secara lahiriah meliputi kecantikan, postur tubuh, penampilan dan sebagainya. Selain penggambaran oleh pengarang, citra fisik tokoh juga diungkapkan pengarang melalui tokoh yang berperan dalam syair. Pada penelitian ini terdapat tiga indikator fisik wanita yaitu kecantikan, postur tubuh, dan penampilan tokoh wanita dalam syair.

\section{Kecantikan}

Kecantikan menurut KBBI adalah keelokan (tentang wajah, muka). Jadi, kecantikan adalah keelokan tentang wajah atau muka tokoh Siti Zubaidah dalam syair Siti Zubaidah. Berikut ini pemaparan tentang kecantikan Siti Zubaidah.

[1]

Dilihat oleh Zubaidah bangsawan

Paras elok tidak berlawan

Cahayanya perisai kilau-kilauan

Seperti bulan dicelah awan

(SSZ, hlm.35)

Pada kutipan 1 di atas disampaikan secara langsung kecantikan Siti Zubaidah. Hal ini terlihat pada kata Paras elok tidak berlawan. Kutipan ini menyatakan kecantikan Siti Zubaidah tidak ada tandingannya. Cahayanya berkilau-kilauan. Hingga diumpakan seperti bulan dicelah awan. Bulan adalah ratu malam yang menghiasi langit. Bulan memiliki cahaya yang paling terang diantara benda langit lainnya ketika malam hari.

[2]

Semayam di atas kursi bertulis

Di bawahnya orang berbaris-baris

Serta berpayung awan beralis

Parasnya itu terlalu majelis

(SSZ, hlm.35)

Pada kutipan 2 di atas disampaikan secara langsung kecantikan Siti Zubaidah. Hal ini terlihat pada kata Parasnya itu terlalu majelis. Kutipan ini menyatakan Siti Zubaidah sangat cantik. Kecantikannya seperti dipayungi awan yang indah.

[3]

Lalu berkata Siti Nur Hidah,

"Mengapakah Tuanku paras yang indah"

Wajah dipandang selakunya gundah 
Meneropong seketika berhenti sudah?”

(SSZ, hlm.35)

Dalam kutipan 3 kecantikan Siti Zubaidah diketahui dari ucapan Siti Nur Hidah, dayang Siti Zubaidah. Siti Nur Hidah bertanya kepada Siti Zubaidah "Mengapakah Tuanku paras yang indah.” Kecantikan Siti Zubaidah tampak dari perkataan Siti Nur Hidah yang menyapanya dengan kata, Tuanku paras yang indah. Hal ini menyatakan bahwa Siti Zubaidah memiliki wajah yang cantik.

Pada kutipan tersebut Siti Zubaidah nampak gundah ketika meneropong kapal yang akan berlabuh. Kemudian dia berhenti meneropong. Melihat keadaan demikian bertanyalah Siti Nur Hidah kepada Siti Zubaidah tentang kegundahannya yang terpancar lewat wajah cantiknya.

[4]

Adapun akan Siti Bestari

Di atas mahligai Hamama Bidadari

Duduk di jendela paginya hari

Wajah bersih wajah berseri

(SSZ, hlm.45)

Kecantikan Siti Zubaidah pada kutipan 4 di atas diketahui dari kata-kata Wajah bersih wajah berseri. Siti Zubaidah memiliki wajah yang bersih dan berseri. Kecantikannya terpancar dari raut wajahnya.

[5]

Dengan pakaian yang indah-indah

Parasnya elok terlalu sigah

(SSZ, hlm.57)

Kecantikan Siti Zubaidah terlihat pada kutipan 5 di atas. Hal ini tampak pada kata-kata Parasnya elok terlalu sigah. Kecantikan Siti Zubaidah tampak dari parasnya yang elok. Sehingga siapa saja yang bertatap muka dengannya pasti akan menyatakan bahwa paras Siti Zubaidah memang cantik.

Berdasarkan kutipan 6 di atas kecantikan Siti Zubaidah diungkapkan dengan kata Elok manis Siti Zubaidah. Kecantikan Siti Zubaidah tidak hanya dilihat dari wajahnya.Tetapi, kecantikannya juga terlihat dari bagaimana Siti Zubaidah menggunakan pakaian yang indah dalam kehidupan sehari-hari.Kecantikan Siti Zubaidah ini membuat siapa saja yang memandangnya menjadi gundah.Sehingga selalu ingin memandangnya.

[7]

Cantik-cantik tiada terperi 
Paras seperti anakkan bidadari

Disinar bulan dengan matahari

Gilang-gemilang wajah berseri

(SSZ, hlm.71)

Kecantikan Siti Zubaidah memang tidak ada bandingannya.Sehingga kecantikannya disetarakan dengan bidadari.Wajahnya bercahaya seperti bulan, benda langit yang paling bersinar ketika malam hari.Wajah Siti Zubaidah juga seperti sinar matahari, benda langit yang paling bercahaya pada siang hari.Hal ini sesuai dengan kutipan 6 berikut.

Cantik-cantik tiada terperi

Paras seperti anakkan bidadari

Disinar bulan dengan matahari

Gilang-gemilang wajah berseri

Kecantikan Siti Zubaidah tidak hanya bersinar seperti bulan atau matahari.Tetapi, kecantikannya diumpamakan seperti benda yang paling terang di bumi ini baik pada siang hari maupun malam hari.Sehingga bisa dikatakan Siti Zubaidah memiliki kecantikan yang tiada terperi.

\section{Postur Tubuh}

Kata postur menurut KBBI adalah bentuk atau keadaan tubuh/perawakan, sedangkan tubuh adalah keseluruhan jasad manusia. Jadi, postur tubuh adalah keseluruhan perawakan manusia dari ujung rambut hingga ujung kaki.

Citra wanita dari segi fisik yang terkait dengan postur tubuh adalah gambaran tubuh/perawatan wanita secara fisik dari ujung rambut hingga ujung kaki. Berikut ini akan dipaparkan postur tubuh Siti Zubaidah yang terdapat dalam syar Siti Zubaidah.

[1]

Dilihat oleh Zubaidah bangsawan

Paras elok tidak berlawan

Cahayanya perisai kilau-kilauan

Seperti bulan dicelah awan

(SSZ, hlm.35)

Pada kutipan 1 di atas memaparkan wajah Siti Zubaidah. Bagian postur tubuh Siti Zubaidah dipaparkan sangat cantik. Hal ini terlihat pada kata Paras elok tidak berlawan. Kutipan ini 
menyatakan kecantikan Siti Zubaidah tidak ada tandingannya. Diumpamakan seperti bulan dicelah awan yang memiliki cahaya berkilau-kilauan.

[2]

Bercelak mata bersifat alis

Kuping seperti awan bertulis

Ekos matanya Baginda tiris

Wajahnya perisai sangat gelis

(SSZ, hlm.37)

Pada kutipan di atas diketahui alis Siti Zubaidah sering memakai celak mata. Kupingnya seperti awan. ekos mata/ekor matanya sangat menawan, dan wajahnya sangat cantik.

[3]

Ada sangat Baginda berhenti

Terdengar kepadanya suara Siti

Didengar Baginda diamat-amati

Membaca Quran nyatalah pasti

(SSZ, hlm.64)

Langgamnya elok suaranya merdu

Seperti bunyi buluh perindu

Halus manis bunyinya merdu

Seperti bercampur gula dan madu

(SSZ, hlm.65)

Postur tubuh Siti Zubaidah yang tampak pada kutipan 3 di atas adalah suara Siti Zubaidah. Berikut ini kutipannya.

Langgamnya elok suaranya merdu

Seperti bunyi buluh perindu

Halus manis bunyinya merdu

Seperti bercampur gula dan madu

Berdasarkan kutipan di atas, suaraSiti Zubaidah diungkapkan sangat merdu ketika membaca Al quran. Hal ini tampak pada langgam suaranya ketika melantunkan ayat-ayat suci Al quran. Suaranya seperti buluh perindu, memikat hati siapa saja yang mendengar. Suaranya halus seperti bercampur gula dan muda. Suara Siti Zubaidah mengandung pemanis alami. Memberi rasa senang kepada siapa saja yang mendengar suaranya.

[4]

Inilah rupanya perempuan sempurna

Sifatnya lengkap tujuh laksana

Sukar dicari barang di mana 
Parasnya elok sedang sederhana

(SSZ, hlm.76)

Sultan Abidin menyatakan Siti Zubaidah adalah perempuan sempurna. Memiliki sifat yang sempurna seperti tujuh laksana.Sehingga seseorang yang memiliki sifat seperti Siti Zubaidah ini sangat langka.Melihat kesempurnaan Siti Zubaidah membuat siapa saja tidak hanya mengagumi keelokan parasnya.Tetapi dia mewakili perempuan yang sempurna di mata laki-laki untuk dijadikan pasangan hidup.Pernyataan di atas sesuai dengan isi kutipan 4 yang menyiratkan kesempurnaan Siti Zubaidah dalam keelokan wajah dan sifatnya.

\section{Penampilan}

Penampilan menurut KBBI yakni dari kata tampil, sesuatu yang dipertontonkan, dikenakan, suatu penampilan maupun gaya. Citra wanita dari segi fisik yang terkait dengan penampilan adalah gambaran penampilan wanita yang ia kenakanan. Berikut ini akan dipaparkan penampilan Siti Zubaidah yang terdapat dalam syar Siti Zubaidah.

\section{[1]}

Elok manis Siti Zubaidah

Patutlah dengan pakaian yang indah

Segala yang memandang berhati gundah

Memandang tidak berkalanya sudah

(SSZ, hlm.58)

Dari kutipan di atas, pada larik kedua dapat digambarkan bagaimana penampilan Siti Zubaidah. Ia mengenakan pakaian yang indah, yang dapat membuat orang yang memandangnya menjadi gundah karena kagum. Siti Zubaidah dikenal sebagai perempuan yang menjaga penampilannya. Ia mengenakan pakaian sesuai situasi dan kondisi, tidak berpakaian lusuh dan tidak mempertontonkan anggota tubuh yang harus tertutup. Kutipan berikut juga menegaskan penampilan Siti Zubaidah:

[2]

Siti ke empat sudah sedia

Memakai kain baju yang mulia

Diiringkan oleh hamba sahaya

Turun sekoci keempatnya dia

Dapat disimpulkan bahwa Siti Zubaidah selalu mempertimbangkan apa yang akan ia kenakan. Sebagai perempuan terhormat ia menjaga penampilan dengan pandai memilih pakaian yang akan dikenakan sesuai dengan situasi dan kondisi. 


\section{SIMPULAN}

Simpulan hasil analisis dari penelitian citra fisik tokoh Siti Zubaidah dalam syair Siti Zubaidah ditemukan ada tiga citra fisik, yakni: (a) kecantikan, (b) postur tubuh, dan (c) penampilan. Diantara ketiga citra tersebut, yang paling dominan adalah citra fisik dari segi kecantikan.Banyak kutipan yang menggambarkan kecantikan dan keelokan tokoh Siti Zubaidah.

\section{SARAN}

Berdasarkan hasil analisis yang telah dilakukan ini. Berikut ini disampaikan beberapa saran terkait dengan penelitian mengenai citra wanita dari segi fisik:

1. Secara praktis, dapat menambah referensi penelitian karya sastra dan menambah pengetahuan pembaca tentang citra wanita dari segi fisik dan feminisme.

2. Secara teoritis, penelitian ini dapat memberikan sumbangan dalam mengaplikasikan ilmu pengetahuan khususnya dibidang satra, khususnya sastra lisan. Penelitian ini juga dapat dijadikan sebagai bahan penelitian sastra untuk meneliti secara lebih dalam lagi dari beberapa aspek yang lain.

\section{DAFTAR RUJUKAN}

Aminuddin, 1991. Pengantar Apresiasi Karya Sastra. Bandung: Sinar Baru Algensindo.

Arikunto, Suharsimi. (1998).Prosedur Penelitian: Suatu Pendekatan Praktek. Jakarta: Rineka Cipta.

Endraswara, Suwardi. 2013. Metodologi Penelitian Sastra. Yogyakarta: CAPS.

Jaruki, Muhammad dan Sri Sayekti. 2010. Syair Siti Zubaidah. Jakarta: Pusat Bahasa Kementrian Pendidikan Nasional.

Lizawati. 2015. Analisis Citra Wanitadalam Novel PerempuanJogjaKaryaAchmadMunif. Volume4. Nomor2.(online).http://download.portalgaruda.org/article.php?article $=498340 \& \mathrm{val}=10211 \& \mathrm{ti}$ tle $=$ ANALISIS $\% 20$ CITRA $\% 20$ WANITA \%20DALAM $\% 20$ OVEL \%20PEREMPUAN\%20J OGJA\%20KARYA\%20ACHMAD\%20MUNIF, diakses pada 22 Juni 2018

Moleong, L. J. (2005). Metode Penelitian Kualitatif. Bandung: PT Remaja Rosdakarya.

Muliana, Dewi. 2016. Citra Perempuandalam Novel Tragedi Gadis Parijs Van Java Karya Ganu Van Dort. Volome 1. Nomor 16. (online). http://download.portalgaruda.org /article.php? article= $42150 \& \mathrm{val}=8476 \&$ title $=$ CITRA $\% 20$ PEREMPUAN $\% 20$ DALAM $\% 20$ NOVEL $\% 20$ TRAGEDI \%20GADIS\%20PARIJS\%20VAN\%20JAVA\%20KARYA\%20GANU\%20VAN\%20DORT, diakses pada 22 Juni 2018 
Sugihastuti dan Suharto. 2016. Kritik Sastra Feminis: Teori dan Aplikasinya. Yogyakarta: Pustaka Pelajar.

Wiyono, Eko Hadi.2007. Kamus Bahasa Indonesia. Planta. 